\title{
Habitat zonation of the sand-burrowing mysids (Archaeomysis vulgaris, Archaeomysis japonica and liella ohshimai), and diel and tidal distribution of dominant Archaeomysis vulgaris, in an intermediate sandy beach at Fukiagehama, Kagoshima Prefecture, southern Japan
}

\author{
TAKumi Nonomura ${ }^{1,4 *}$, Yasuhiro Hayakawa ${ }^{1}$, Yusuke SudA $^{2,5} \&$ Jun OhtOmI $^{3}$ \\ ${ }^{1}$ Laboratory of Fisheries Biology and Environment, Graduate School of Fisheries Science, National Fisheries University, 2-7-1 \\ Nagata-Honmachi, Shimonoseki city, Yamaguchi 759-6595, Japan \\ ${ }^{2}$ Department of Fishery Science and Technology, National Fisheries University, 2-7-1 Nagata-Honmachi, Shimonoseki city, \\ Yamaguchi 759-6595, Japan \\ ${ }^{3}$ Faculty of Fisheries, Kagoshima University, 4-50-20 Shimoarata, Kagoshima city, Kagoshima 890-0056, Japan \\ ${ }^{4}$ Present address: Plankton Laboratory, Ocean Research Institute, The University of Tokyo, 1-15-1 Minamidai, Nakano-ku, \\ Tokyo 164-8639, Japan \\ ${ }^{5}$ Present address: Department of Applied Aquabiology, National Fisheries University, 2-7-1 Nagata-Honmachi, Shimonoseki \\ city, Yamaguchi 759-6595, Japan
}

Received 2 November 2005; Accepted 30 December 2006

\begin{abstract}
Distribution patterns of the three species of sand-burrowing mysids, Archaeomysis vulgaris, Archaeomysis japonica and Iiella ohshimai were investigated, and also the diel and tidal distribution patterns of the dominant mysid $A$. vulgaris were investigated in the surf zone of an exposed and mesotidal sandy beach at Fukiagehama, Kagoshima Prefecture, southern Japan. The morphodynamic state of the beach was an intermediate type with a low-tide terrace or ridge/runnel. Habitat zonation was recognized among the three species during the entire study period (May and October of 2002 and 2003). A. vulgaris occurred from the high-water shoreline to the low-water shoreline during the daytime, whereas A. japonica was observed off the low-water shoreline and I. ohshimai was found far from the longshore bar. Habitats of A. vulgaris shifted along the beach slope, depending on the tidal changes at the shoreline. However, at low water in May of 2002 and 2003, most individuals of $A$. vulgaris were distributed in the intertidal runnel and on the lowtide terrace, rather than off the low-water shoreline. A. vulgaris had the highest population density of the three species, and fluctuations in its total mean density in the surf zone were estimated at each tide in May of 2003. These ranged from 2,956 indiv. $\mathrm{m}^{-2}$ at low water at night to 172 indiv. $\mathrm{m}^{-2}$ at middle water during the daytime. Distribution patterns characteristic of $A$. vulgaris are ecologically interpreted in relation to beach morphology, water flow regimes in the surf zone, and avoidance of fish-predation pressure.
\end{abstract}

Key words: Archaeomysis, Iiella, intermediate sandy beach, intertidal runnel, low-tide terrace

\section{Introduction}

Of the sand-burrowing mysids occurring in the surf zone of sandy beaches of various beach-types throughout the world (Brown \& McLachlan 1990), the genus Archaeomysis is typical and abundant all along Japan's sandy coastline (Hanamura 1997). Six species presently comprise this

*Corresponding author: Takumi Nonomura; E-mail, nonomura@ori.utokyo.ac.jp genus. Five species of the species (Archaeomysis vulgaris, Archaeomysis kokuboi, Archaeomysis articulata, Archaeomysis japonica, Archaeomysis ochotensis), excluding Archaeomysis grebnitzkii in the USA, have been found in Japan (Hanamura 1997). Despite A. vulgaris being dominant in southern Japan, biological and ecological information about it is very scarce. Although early taxonomic and biogeographic studies suggested differences in habitat types between A. vulgaris and A. japonica (Jo \& Hanamura 1993, Hanamura 1997), detailed distribution patterns of the con- 
geners remain uncharacterized.

To understand the distribution patterns of these mysids, it is necessary to know the beach morphodynamic states of each individual sandy beach, because changes in beach morphodynamic states directly determine the microdistribution patterns of macroscopic animals (McLachlan \& Hesp 1984, Brown \& McLachlan 1990, Harvey 1998, Layman 2000, Marcomini et al. 2002). The term "beach morphodynamics" was defined as the mutual adjustment of topography and fluid dynamics involving sediment transport (cf. Wright \& Thom 1977). Therefore, this term implies mutual interaction between waves (tides/currents) and beach morphology, such that the wave action modifies the beach morphology, which in turn will modify the waves and so on (Short 1999). In terms of the beach morphodynamic states, sandy beaches have been roughly categorized into reflective (steep), intermediate and dissipative types, which are related to beach morphology and beach slopes characteristic of each sandy beach.

With the exception of some ecological studies on sandburrowing mysids in high-energy dissipative sandy beaches facing open coasts (McLachlan 1990, Hanamura 1999), most previous studies have been carried out on low-energy reflective beaches which are found inside estuaries, bays and harbors (Matsudaira et al. 1952, Takahashi \& Kawaguchi 1995, 1997, Kaneko \& Omori 2003). So, it is also necessary to understand their distribution patterns on high-energy intermediate sandy beaches that are found on open coasts, because the distribution patterns of mysids, one of the most abundant prey organisms on sandy beaches, are of ecological importance.

In order to present ecological information about sandburrowing mysids in an intermediate sandy beach, this paper describes (1) the horizontal distribution patterns of $A$. vulgaris and $A$. japonica, together with the less abundant sand-burrowing mysid, Iiella ohshimai, and also deals with (2) details of the diel and tidal distribution patterns of the dominant mysid A. vulgaris at Fukiagehama. Distribution patterns characteristic of $A$. vulgaris from the results are ecologically interpreted in relation to beach morphology, water flow regimes in the surf zone, and avoidance of fishpredation pressure.

\section{Materials and Methods}

\section{Study area and beach morphology}

The study was done at Fukiagehama on the western coast of Kagoshima Prefecture, Kyushu, southern Japan (31 $29^{\prime}$ $\mathrm{N}, 130^{\circ} 19^{\prime} \mathrm{E}$ ) (Fig. 1). Fukiagehama is one of the longest sandy beaches in Japan and has a ca. $45 \mathrm{k}$ m coastline, opening broadly to the East China Sea. The bottom substratum was largely composed of medium grained and wellsorted sand (the mean of median particle diameters, $\operatorname{Md} \phi$ : $295 \mu \mathrm{m}$; the mean of sorting coefficients: 0.57 ), and the intertidal zone was ca. $100 \mathrm{~m}$ in width with a $1: 45$ beach

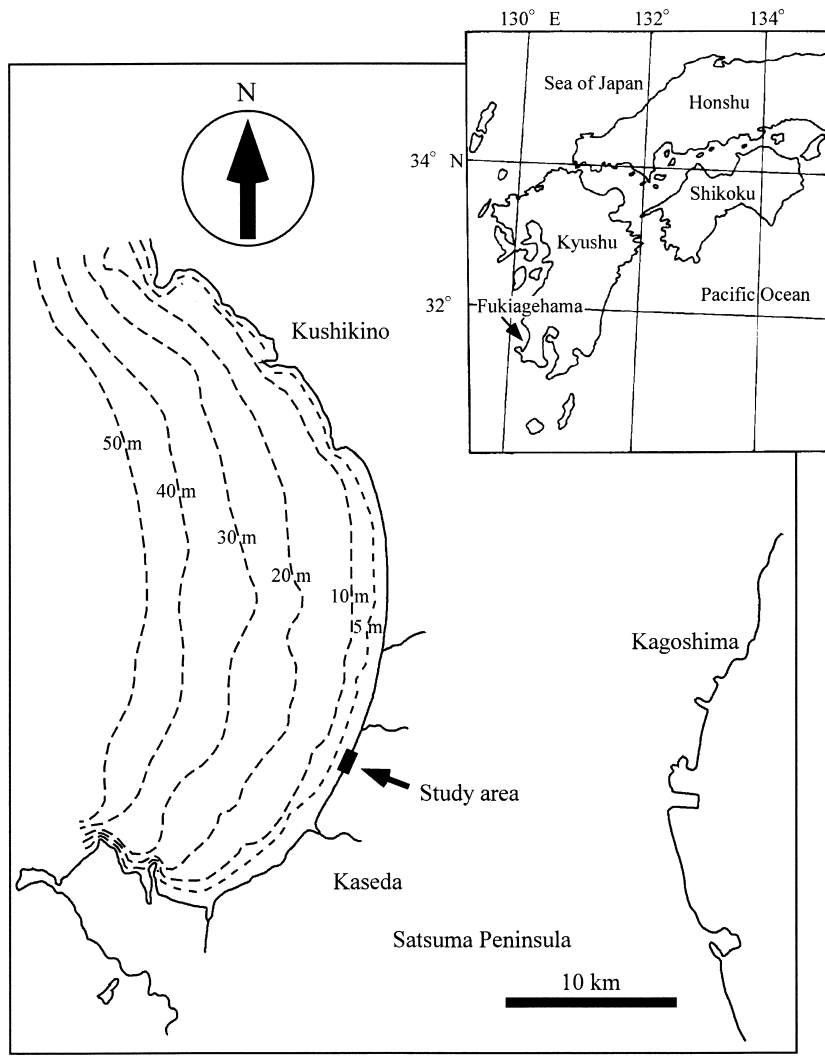

Fig. 1. Map showing the study area in Fukiagehama, Kagoshima Prefecture, Kyushu, southern Japan.

slope ratio (Nonomura et al. unpubl.).

Figure 2 introduces beach morphology for all the sampling stations in the study area on each sampling date (15-16 May 2002, 23 October 2002, 17 May 2003 and 27 October 2003), because of seasonal changes in beach morphology. Sampling stations in the surf zone were coded as follows: H1-H5: high-water shoreline; HM1-HM5: higher middle-water shoreline; LM1-LM5: lower middle-water shoreline; R1-R4: intertidal runnel; LTT: low-tide terrace; HL1-HL5: higher low-water shoreline; LL1-LL5: lower low-water shoreline; B: longshore bar. In this study, 'surf zone' refers to the area between the shoreline and breaker zone over the longshore bar, the usual width of the surf zone being approximately 100 to $200 \mathrm{~m}$. Beach slope was steeper at Stns H1-H5 than at any other stations. Thus, wave condition adjacent to the high-water shoreline was harsh during high water. In contrast, waves were of low energy from middle water to low water. The study area has been reported as an intermediate type characterized by a low-tide terrace or ridge/runnel (cf. Nakane et al. 2005), according to the beach morphodynamic state classification by Short (1999). The maximum tidal range was ca. $3 \mathrm{~m}$ at spring tide. The low-tide terrace often appeared above the water level at low water. Off the low-tide terrace, the longshore bar was found running parallel to the coastline. Two shallow troughs emerged at low water, the intertidal runnel between the backshore and the low-tide terrace, and the in- 

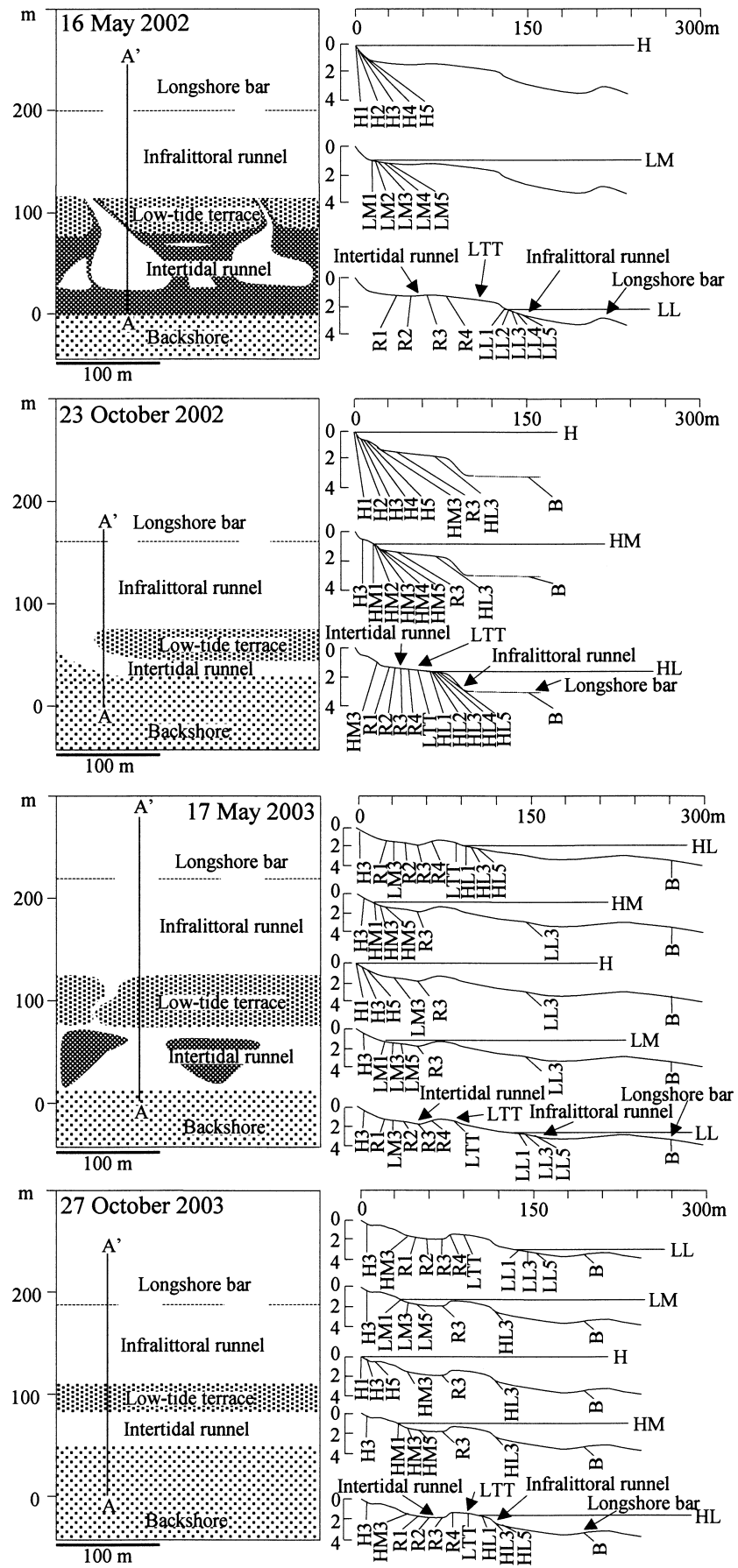

Fig. 2. Beach morphology at low water (left) and profiles (right) of the line $\mathrm{A}-\mathrm{A}^{\prime}$ on each sampling date. Distances $(\mathrm{m})$ from the high-water shoreline are shown on the left and top, respectively. Height $(\mathrm{m})$ from high-water level is also shown to the left of the beach profile.

fralittoral runnel between the low-tide terrace and the longshore bar. The intertidal runnel, the low-tide terrace and the infralittoral runnel are typical of the morphology of intermediate sandy beaches (cf. Short 1999). Seepage of groundwater was observed in the intertidal runnel during low water. The infralittoral runnel was often observed to have a connection with the open sea. The water-depth in the intertidal runnel was less than $5 \mathrm{~cm}$ at low water, while that in the infralittoral runnel was more than $40 \mathrm{~cm}$ at low water. The intertidal runnel sometimes lacked surface water depending on the low-water level and/or beach morphology, while the infralittoral runnel remained covered with sea water. These structures seasonally occurred in spring and fall. Mean salinity and mean water-temperature at low water was $18.6 \mathrm{psu}$ and $23.2^{\circ} \mathrm{C}$ in the intertidal runnel, and $32.2 \mathrm{psu}$ and $22.2^{\circ} \mathrm{C}$ in the infralittoral runnel, because of the low salinity of the groundwater seepage (Nonomura et al. unpubl.).

\section{Mysid sampling and data analysis}

Sampling was conducted at approximately 3-hr intervals according to changes in tidal levels (Fig. 3). In 2002 sampling was conducted three times, from high water to low water later during the daytime; with one extra sampling for practice in the use of the sampling gear at low water on 15 May. In 2003 sampling was conducted five times, from low water in the nighttime to low water in the daytime. The tidal phase was a spring tide and the weather was fine throughout the sampling. Tidal levels and local time came from the data of Kushikino City $\left(31^{\circ} 43^{\prime} \mathrm{N}, 130^{\circ} 16^{\prime} \mathrm{E}\right)$ (JCG 2001, JCG 2002).

Figure 4 is a schematic representation of sampling coverage with three kinds of sampling gear. Sampling was done between the high-water shoreline and the longshore bar. Mean water-depths hs of Stns H3, LM3/HM3, R3, LL3/HL3 and B at high water were 0.4, 1.3, 1.5, 2.7 and $3.6 \mathrm{~m}$, respectively. The mean distance from the high-water shoreline to the longshore bar was $200 \mathrm{~m}$. Stations adjacent to the shoreline (e.g. Stns H1-H5) were set at intervals of $3 \mathrm{~m}$ in 2002 and $6 \mathrm{~m}$ in 2003. A sledge net, a NORPAC net and a quadrat were used for the mysid sampling. A $50 \mathrm{~cm}$ wide and $10 \mathrm{~cm}$ high sledge net (mesh size of $335 \mu \mathrm{m}$ ) with a chain was used to collect mysids just above and burrowing in the sandy bottom. A NORPAC type plankton net (mesh size of $335 \mu \mathrm{m} ; 45 \mathrm{~cm}$ mouth diameter; $1.8 \mathrm{~m}$ long) was towed to collect mysids in the water column. After the ebb tide went out, a quadrat $\left(0.04 \mathrm{~m}^{2}\right)$ was used in the intertidal zone to collect mysids on the surface of the sandy bottom or buried in sand up to $5 \mathrm{~cm}$ depth, because most individuals of Archaeomysis vulgaris were in the intertidal runnel at low water (as will be mentioned later). Around the shoreline, the sledge net and the plankton net were towed once each over a distance of $3 \mathrm{~m}$. At offshore stations, the nets were towed twice over a distance of $5 \mathrm{~m}$ because of the low density of mysids. The plankton net was towed in two ways: a surface tow and an oblique tow from the bottom to the water surface to cover the whole water column. All the tows were made parallel to the shoreline.

Mysids were fixed in 10\% sea-water formalin and sorted into species and different sexual maturity stages (mature female, immature female, mature male, immature male and 

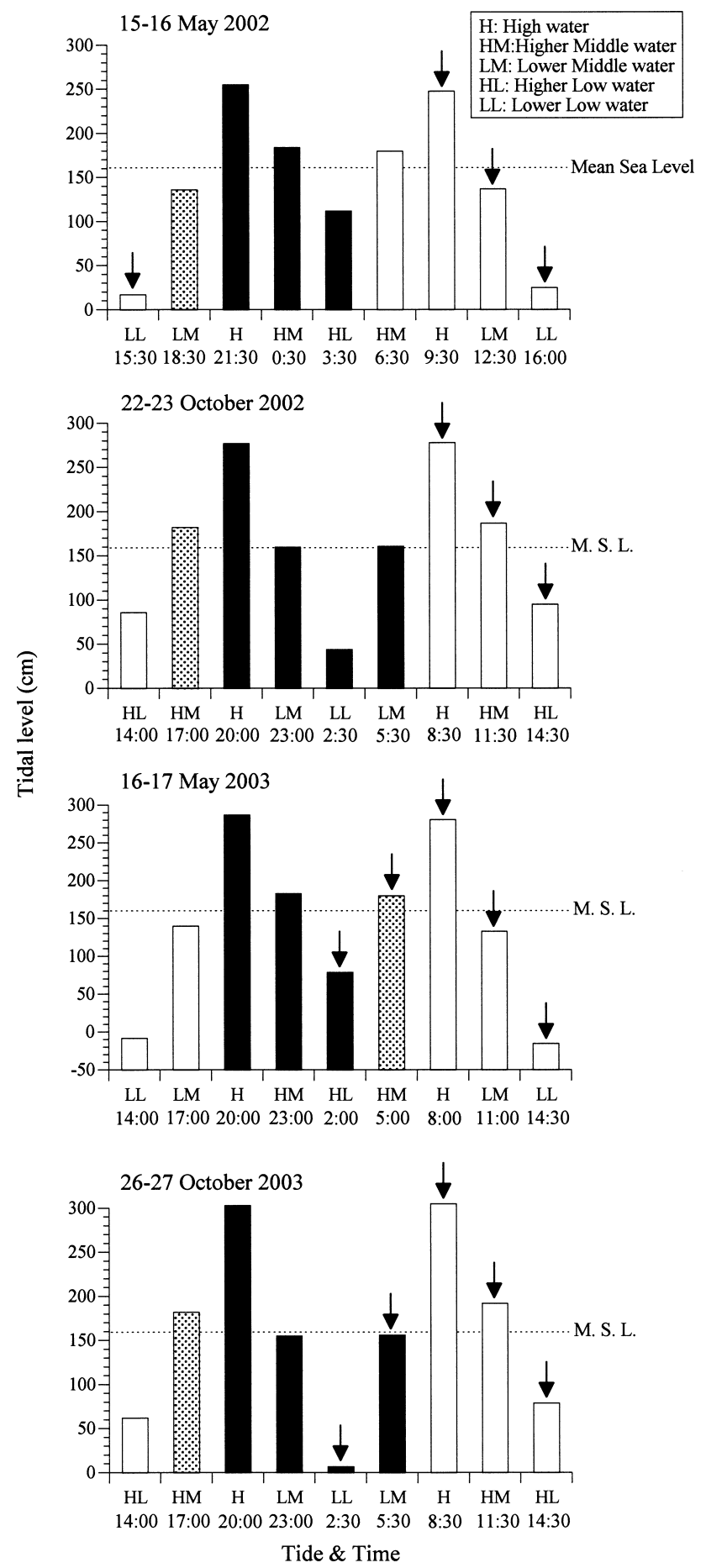

Fig. 3. Tidal level and sampling time. Arrows indicate the sampling carried out. Black, white and mesh bars indicate night, day and dusk/dawn, respectively.

juvenile) after Takahashi \& Kawaguchi (1996) and Nonomura et al. (2005). The distance (m) from the high-water shoreline for each individual mysid and the density (indiv. $\mathrm{m}^{-2}$ ) of mysids were calculated, with the data being examined using a Wilcoxon-Mann-Whitney test, a KruskalWallis test with a nonparametric multiple comparison and a Chi-square test for proportions after Zar (1999).

\section{Calculation of weighted mean distance from high-water shoreline}

In addition, the weighted mean distance from the highwater shoreline (WMDi, m), adapted from Shimode \& Shirayama (2006), was used to examine differences in horizontal distribution among mysids, the diel and tidal distribution of the dominant species $A$. vulgaris, and the developmental stage-specific distribution of $A$. vulgaris. The WMDi was calculated as follows:

$$
\text { TMDe }=\frac{\sum n_{i} d_{i}}{\sum d_{i}}
$$

where $n_{i}$ is the observed density (indiv. $\mathrm{m}^{-2}$ ) at $d_{i}$, distance (m) from the high-water shoreline.

\section{Estimation of total mean density of Archaeomysis vul-} garis in the surf zone

Total mean density (TMDe, indiv. $\mathrm{m}^{-2}$ ) was calculated to estimate fluctuations of the total population of $A$. vulgaris, collected by a sledge net, a NORPAC net and a quadrat, in the surf zone. If $A$. vulgaris individuals only migrated inside the surf zone without any losses or gains, the population would be conserved and the TMDe would be nearly constant at each tide. On the other hand, if individuals were transported out of the surf zone by surf zone currents (bed return currents, rip currents and longshore currents), patchily distributed and/or also subjected to high predationpressure by fishes and crabs, the TMDe could fluctuate considerably. Therefore in order to assess the fluctuation in distribution patterns of $A$. vulgaris, it is necessary to estimate its TMDe in the surf zone at each tide. This will also help to evaluate the accuracy of density measurements in this perturbed surf zone environment. The TMDe was calculated as follows:

$$
W M D i=\frac{\sum n_{j} d_{j}}{\sum n_{j}}
$$

where $n_{j}$ is the observed density (indiv. $\mathrm{m}^{-2}$ ) at $d_{j}$, representative distance $(\mathrm{m})$ covered by each sampling station. The representative distance $d_{j}$ is equivalent to a half distance between adjacent sampling stations. The summation of $d_{j}$ is nearly equal to the surf-zone distance (ca. 200-300 m).

\section{Results}

Horizontal distribution patterns of Archaeomysis vulgaris, Archaeomysis japonica and Iiella ohshimai

The three species of sand-burrowing mysids, Archaeomysis vulgaris, Archaeomysis japonica and Iiella ohshimai occurred throughout the study period. Figure 5 indicates the horizontal distribution patterns of the three species at each 


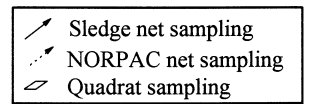

$\varnothing$ Quadrat sampling

Night
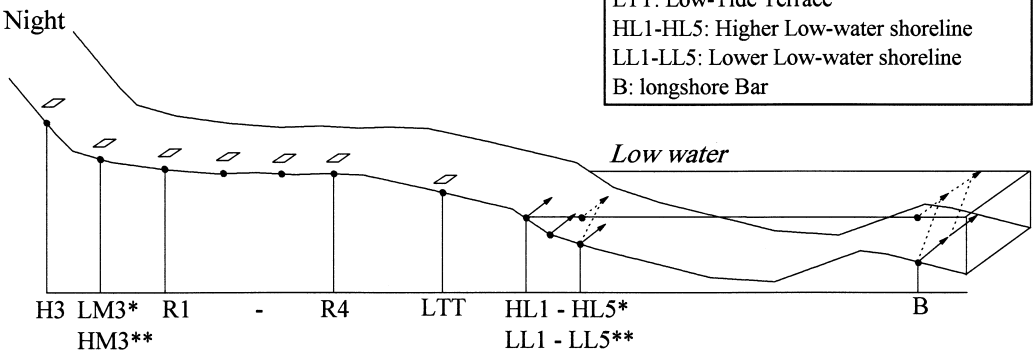

Dawn
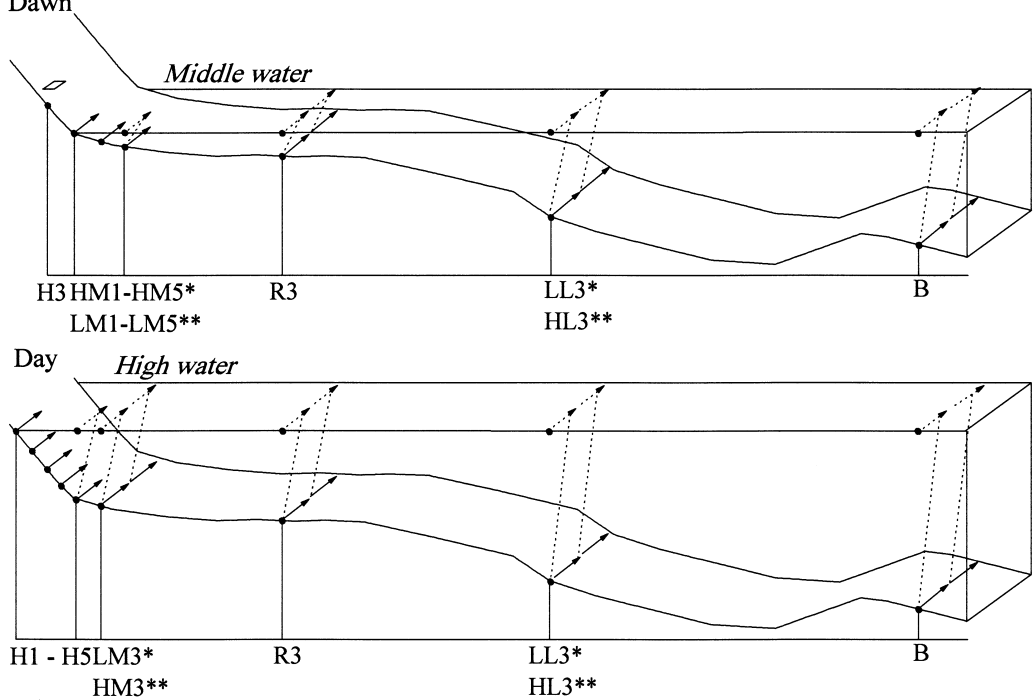

Day

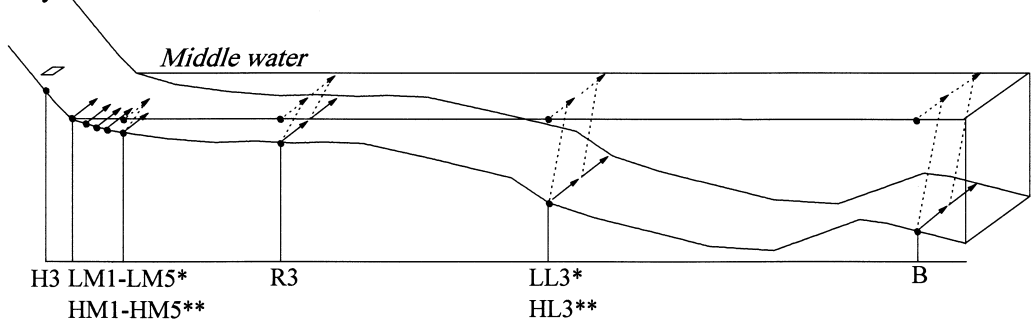

Day

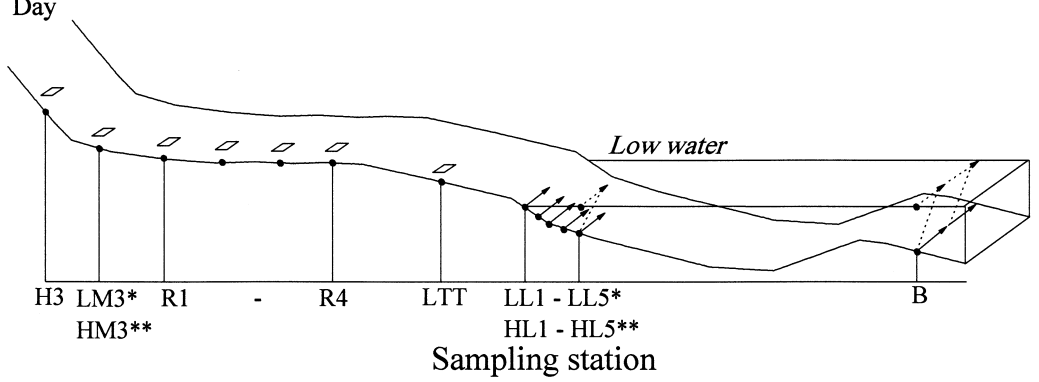

Fig. 4. Schematic representation of sampling coverage at each tide at Fukiagehama. *: sampling stations in May, **: stations in October, and the others are common stations.

station. Averaged density in Fig. 5 was not the TMDe, but was calculated from the observed density, only when the species occurred. It was shown that most $A$. vulgaris occurred in the intertidal zone from the high-water shoreline (Stns H1-H5) to the higher or lower low-water shoreline
(Stns HL1-HL5/LL1-LL5), and few were observed off the longshore bar (Stn B). Archaeomysis japonica occurred mainly in the infralittoral zone off the higher or lower lowwater shoreline (Stns HL1-HL5/LL1-LL5), where it was often more abundant than A. vulgaris, but was scarce in the 


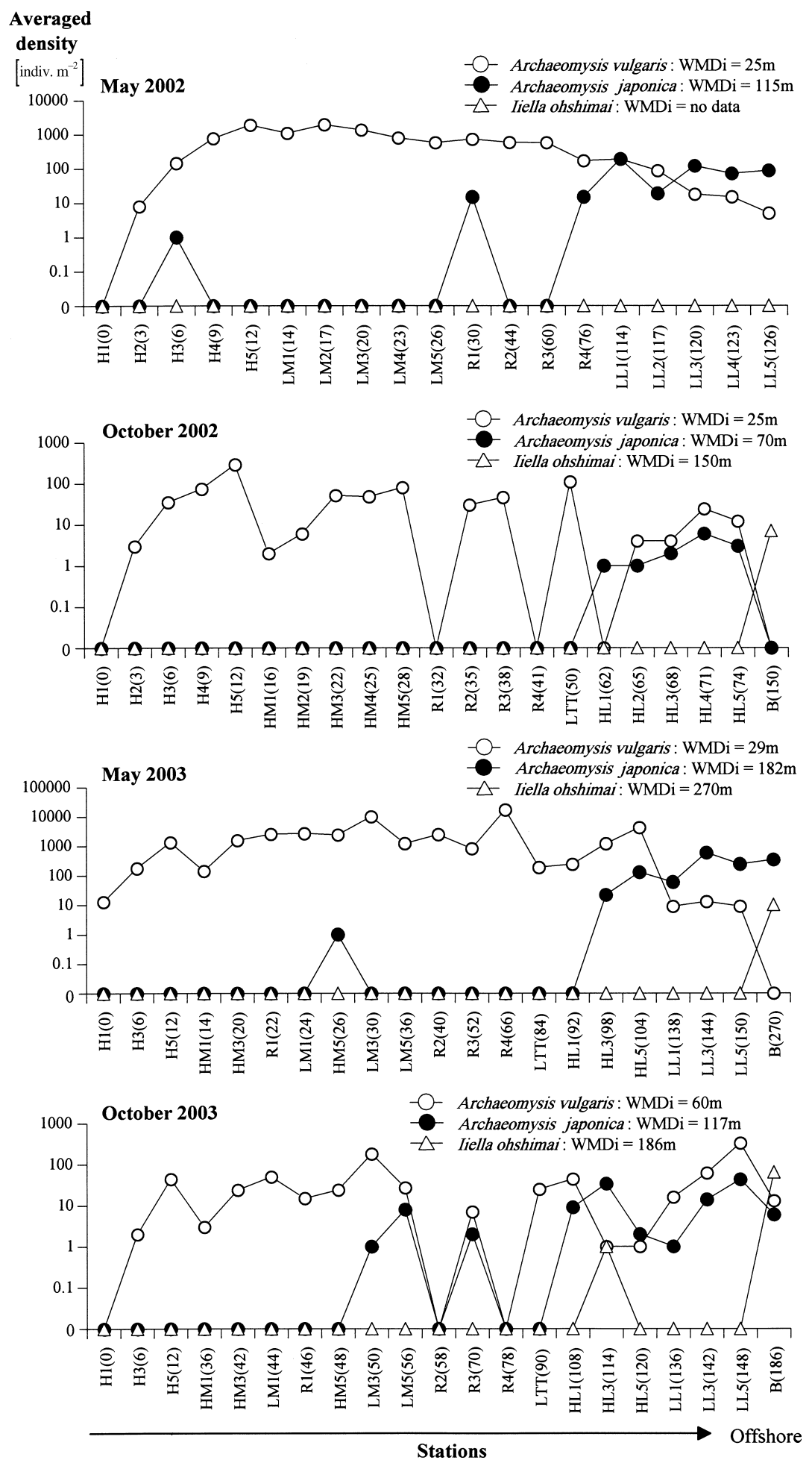

Fig. 5. Horizontal distribution patterns of Archaeomysis vulgaris, Archaeomysis japonica and Iiella ohshimai in the surf zone at Fukiagehama. Numbers in parentheses are the distance from the high-water shoreline. Note that values are averaged densities on a logarithmic scale, except for zero. The WMDi of year 2003 was calculated from the data for daytime only, and this excluded data from night and dawn.

intertidal zone. A. vulgaris and A. japonica distributions often overlapped in the higher or lower low-water shoreline (Stns HL1-HL5/LL1-LL5). Differences in distance from the high-water shoreline between $A$. vulgaris and A. japonica were supported by Wilcoxon-Mann-Whitney tests $(p<0.05)$ for each sampling date. Iiella ohshimai was found only off the longshore bar (Stn B). The mean WMDi of $I$. ohshimai $(202 \mathrm{~m})$ was larger than for A. vulgaris $(35 \mathrm{~m})$ or A. japonica $(121 \mathrm{~m})$, but nonparametric comparisons of $I$. ohshimai to A. vulgaris and A. japonica were not carried 
out because the sample size was small. These results suggest habitat zonation among the three species in the surf zone at Fukiagehama.

Diel and tidal horizontal distribution patterns of $\mathrm{Ar}$ chaeomysis vulgaris

WMDi during the daytime for the population of $A$. vulgaris at high water, middle water and low water is shown in Table 1. No significant difference (Kruskal-Wallis test, $p>0.05$ ) in the WMDi was noted among sampling dates (May 2002, October 2002, May 2003 and October 2003). The mean WMDi for each tide during the daytime was

Table 1. WMDi (weighted mean distance) from the high-water shoreline for the population of Archaeomysis vulgaris at high water, middle water and low water during the daytime.

High water Middle water* Low water*

\begin{tabular}{llll}
\hline May 2002 & 11 & 19 & 55 \\
October 2002 & 13 & 31 & 51 \\
May 2003** & 20 & 29 & 31 \\
October 2003** & 18 & 48 & 78 \\
Mean & 16 & 32 & 54
\end{tabular}

* Middle water is used as a synonym of higher or lower middle water, and the same applies to low water.

** Night-dawn data of Year 2003 was excluded from this table, because of nonparametric comparisons among sampling dates.
$16 \mathrm{~m}$ at high water, $32 \mathrm{~m}$ at middle water and $54 \mathrm{~m}$ at low water. These results suggest that the habitat of $A$. vulgaris shifted along the beach slope, depending on the tidal changes in the shoreline.

An example of diel and tidal horizontal distribution patterns of A. vulgaris at different sexual maturity stages in May of 2003 is shown in Fig. 6. During flood tide from night $(02: 00)$ to dawn $(05: 00)$, the position of peak abundance of A. vulgaris shifted shoreward in accordance with the tidal movement of the shoreline and the WMDi also changed from $67 \mathrm{~m}$ to $27 \mathrm{~m}$. However, during ebb tide during the day (08:00-14:30), A. vulgaris showed slight tidal shifts and the WMDi was $20 \mathrm{~m}$ at high water, $29 \mathrm{~m}$ at lower middle water and $31 \mathrm{~m}$ at lower low water. At nighttime low water (WMDi:67 m), A. vulgaris had a wider distribution than during daytime low water (WMDi:31 m) because of its nocturnal swimming activity in the water column.

At higher low water, at night $(02: 00), 87 \%$ of $A$. vulgaris were found in the intertidal runnel (Stns R1-R4) above the tide level, rather than at Stns HL1-HL5 beneath the tide level, with the greatest abundance at Stn R4. At higher middle water, at dawn $(05: 00)$, the peak abundance shifted shoreward from Stns R4 to HM5, moving with the flood tide. At high water, at about 08:00 in the morning, most A. vulgaris occurred at stations $\mathrm{H} 3, \mathrm{H} 5$ and LM3, which were off Stn H1. At lower middle water, just before noon, the peak abundance was at Stn LM1. Later at lower low water, $99.9 \%$ of $A$. vulgaris were found in the intertidal

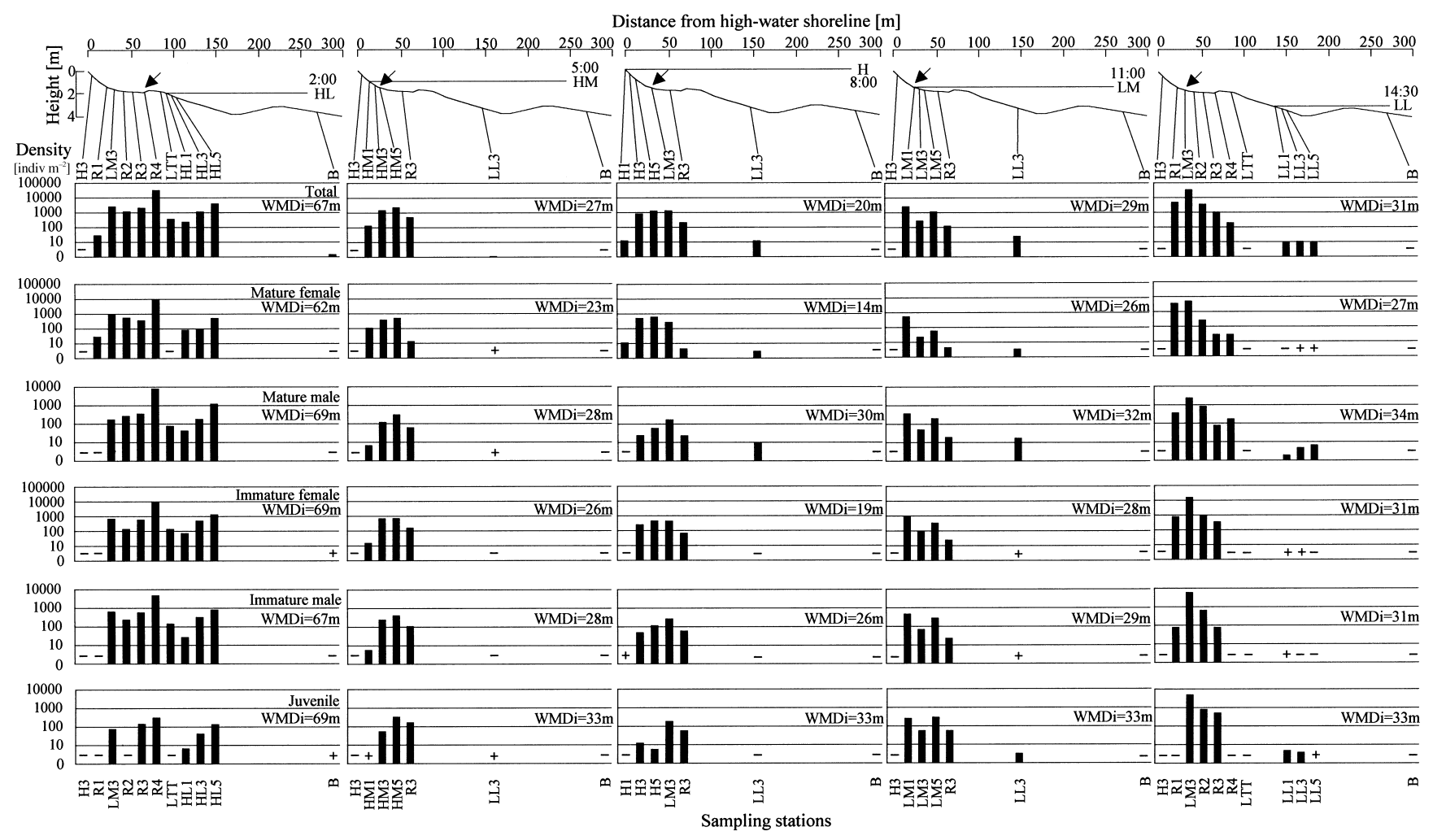

Fig. 6. Diel and tidal horizontal distribution patterns of Archaeomysis vulgaris in May 2003 at Fukiagehama. Note that values observed are on a logarithmic scale, except for zero. Arrow: peak abundance position; $+:<1$ indiv. $\mathrm{m}^{-2}$; - : no mysids collected. 


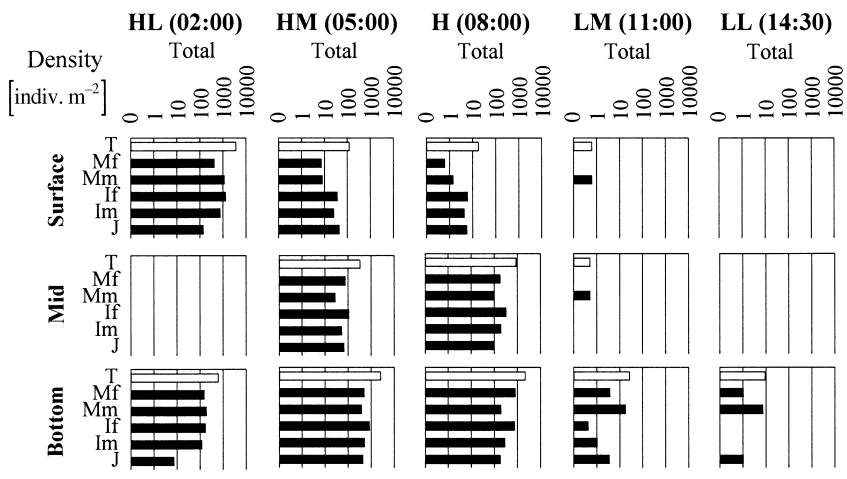

Fig. 7. Diel and tidal vertical distribution patterns of Archaeomysis vulgaris in May 2003 at Fukiagehama. Blanks indicate no mysids collected, but sampling of mid layer was not carried out at Stn HL5 of HL or Stn LL5 of LL because of the shallow waterdepth. Note that values in each layer are on a logarithmic scale, except for zero. T: total; Mf: mature female; Mm: mature male; If: immature female; Im: immature male; J: juvenile.

runnel (Stns R1-R4), with the peak at the shoreward station (Stn LM3) above the tide level.

Although there were no marked differences in distribution between the WMDi of the five sexual maturity stages of A. vulgaris (Kruskal-Wallis test, $p>0.05$ ), mature females (mean WMDi: $30 \mathrm{~m}$ ) had a tendency to occur more shoreward than the other stages (juveniles: $40 \mathrm{~m}$, mature males: $39 \mathrm{~m}$, immature males: $36 \mathrm{~m}$ and immature females: $35 \mathrm{~m}$ in mean WMDi).

The diel and tidal horizontal distribution patterns of $A$. vulgaris in May of 2002 were similar to those during May of 2003. However, the patterns in October differed from those in May because at low water A. vulgaris occurred mainly in the low-tide terrace (Stn LTT) and the higher or lower low-water shorelines (Stns HL1-HL5/LL1-LL5), instead of the intertidal runnel, without differences in the WMDi between sampling dates (Table 1; Kruskal-Wallis test, $p>0.05$ ).

\section{Diel and tidal vertical distribution patterns of Archaeomysis vulgaris}

Vertical distribution patterns of $A$. vulgaris were examined using the data of May and October of 2003, but the sample size in October was small. Figure 7 shows the vertical distribution patterns in relation to diel and tidal changes for A. vulgaris in May of 2003, where the densities (indiv. $\mathrm{m}^{-2}$ ) in the surface, mid and bottom layers are calculated from the total individuals estimated in each layer, and according to the tides. Data from the surface and mid layers are from the NORPAC net, and those at the bottom from the sledge net. As shown at higher low water (HL), at night (02:00), $86 \%$ of $A$. vulgaris were found in the surface layer, whereas at higher middle water (HM), at dawn $(05: 00), 85 \%$ were in the bottom layer. After dawn, $71-100 \%$ were collected in the bottom layer
Table 2. Comparing vertical distributions of the five sexual maturity stages of Archaeomysis vulgaris in the water column, using the data collected in May 2003 by sledge net sampling $(0-10 \mathrm{~cm}$ layer from bottom) and NORPAC net sampling (higher than $10 \mathrm{~cm}$ layer from bottom). Numbers in parentheses are density values (indiv. $\mathrm{m}^{-2}$ ).

\begin{tabular}{|c|c|c|c|}
\hline \multirow[t]{2}{*}{ Category* } & \multirow{2}{*}{$\begin{array}{l}\text { Height from } \\
\text { the bottom } \\
(\mathrm{cm})\end{array}$} & \multicolumn{2}{|c|}{ Proportion (\%) } \\
\hline & & $\begin{array}{l}\text { Night } \\
(02: 00)\end{array}$ & $\begin{array}{c}\text { Day } \\
(08: 00)\end{array}$ \\
\hline \multirow[t]{2}{*}{ Mature $q$} & more than 10 & $74.0(409)$ & $18.3(175)$ \\
\hline & $0-10$ & $26.0(144)$ & $81.7(780)$ \\
\hline \multirow[t]{2}{*}{ Juvenile } & more than 10 & $95.1(135)$ & $34.9(91)$ \\
\hline & $0-10$ & $4.9(7)$ & $65.1(170)$ \\
\hline \multirow[t]{2}{*}{ Mature $\widehat{0}$} & more than 10 & $86.0(1095)$ & $33.5(92)$ \\
\hline & 0-10 & $14.0(178)$ & $66.5(183)$ \\
\hline \multirow[t]{2}{*}{ Immature $q$} & more than 10 & $88.6(1246)$ & 30.7 (318) \\
\hline & $0-10$ & $11.4(161)$ & 69.3 (717) \\
\hline \multirow[t]{2}{*}{ Immature ${ }^{\star}$} & more than 10 & 86.5 (734) & $40.3(186)$ \\
\hline & $0-10$ & $13.5(115)$ & $59.7(275)$ \\
\hline
\end{tabular}

* Partitions between categories were based on comparisons at night.

(08:00-14:30). In October 2003, also, nocturnal swimming activity was observed in the water column for $A$. vulgaris, and swimming activities were also observed for $A$. japonica and I. ohshimai.

For the data at night $(02: 00)$ at higher low water (HL) and the data during the day $(08: 00)$ at high water $(\mathrm{H})$ in May 2003, a comparison of the vertical distribution of the five different sexual maturity stages of $A$. vulgaris was carried out (Table 2). There were marked differences in the vertical distributions among the developmental stages (Chisquare tests, $p<0.05)$. At night $(02: 00)$, the population of A. vulgaris was divided into three groups (mature females, juveniles and others) (Tukey-type multiple comparisons, $p<0.05)$. During the day $(08: 00)$, the population was divided into two groups (mature females and others) (Tukeytype multiple comparisons, $p<0.05$ ). Mature females of $A$. vulgaris had a higher proportion of the population in the $0-10 \mathrm{~cm}$ layer altitude from the bottom than the others, while the juveniles had a higher proportion of the population in the water column at an altitude higher than $10 \mathrm{~cm}$.

\section{Changes in total mean density (TMDe) of Archaeomysis vulgaris in the surf zone}

Total mean density (TMDe) of $A$. vulgaris at each developmental stage fluctuated at each tide (Fig. 8). For example, the TMDe in May of 2003 of animals from juvenile to mature stages was estimated to be 2,956 indiv. $\mathrm{m}^{-2}$ at higher low water in the nighttime, compared with 241, 190 and 172 indiv. $\mathrm{m}^{-2}$ at higher middle water (dawn), high water 

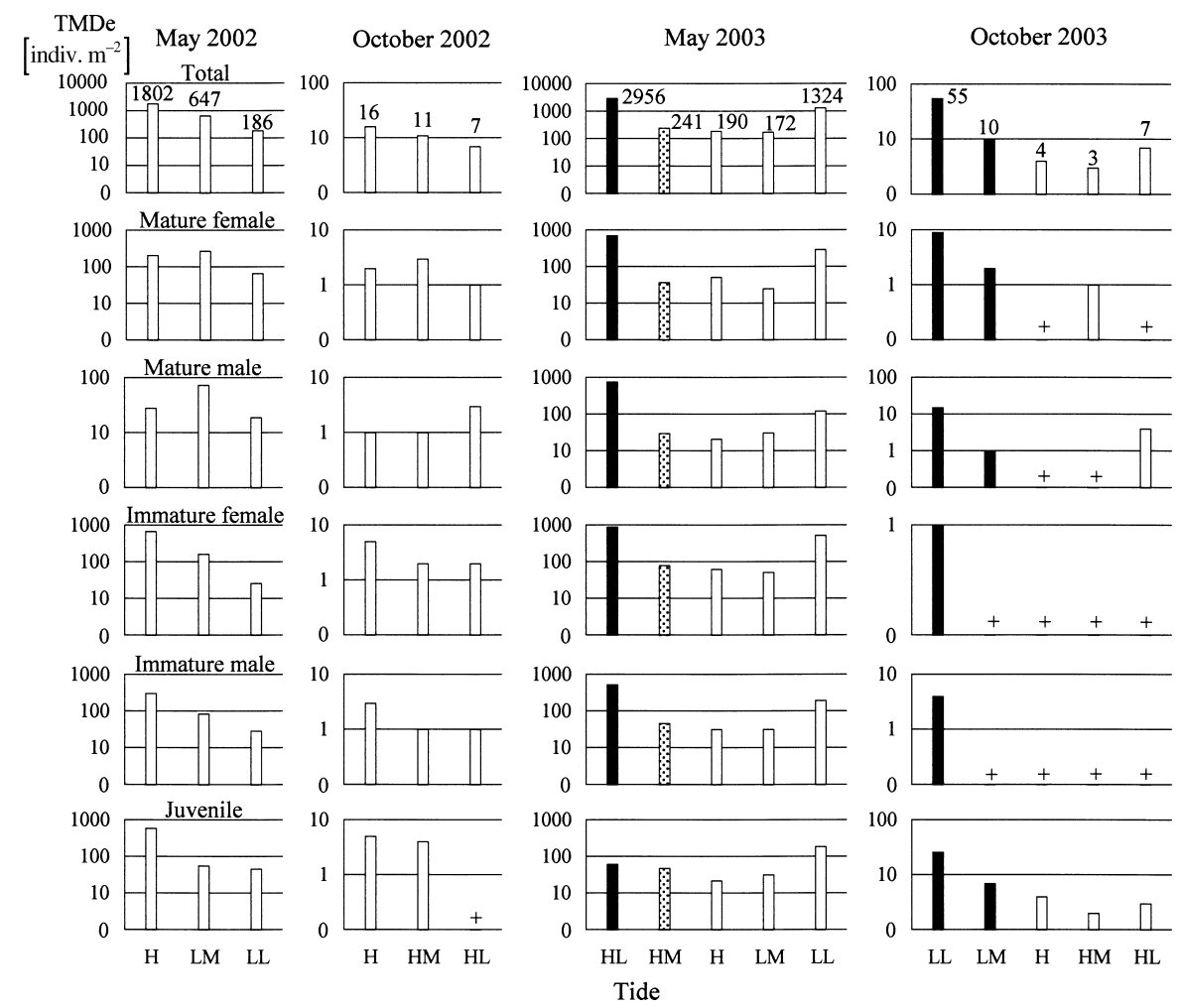

Fig. 8. Changes in Total mean density (TMDe) of Archaeomysis vulgaris in the surf zone at Fukiagehama. Note that values are on a logarithmic scale, except for zero. Black bar: night; mesh bar: dawn; white bar: day; $+:<1$ indiv. $\mathrm{m}^{-2}$.

(daytime) and lower middle water (daytime), respectively. By the time of lower low water later in the daytime, the TMDe was 1,342 indiv. $\mathrm{m}^{-2}$. Estimated TMDe during each tide usually fluctuated several times, up to 17 times at most, throughout the study period.

TMDe of $A$. vulgaris was higher than $A$. japonica during the study period (Wilcoxon-Mann-Whitney test, $p<0.05$ ). In addition, for both species the TMDe in May 2003 ( $A$. vulgaris: $172-2956$ indiv. $\mathrm{m}^{-2}$, A. japonica: $13-709.0$ indiv. $\mathrm{m}^{-2}$ ) was higher than in October 2003 (A. vulgaris: 3-55 indiv. $\mathrm{m}^{-2}, \quad$ A. japonica: $0.2-25.5$ indiv. $\mathrm{m}^{-2}$ ) (Wilcoxon-Mann-Whitney test, $p<0.05$ ).

\section{Discussion}

The daytime distribution of Archaeomysis vulgaris was observed from the high-water shoreline to the low-water shoreline, while Archaeomysis japonica occurred mainly off the low-water shoreline. This suggested that $A$. vulgaris was an intertidal species and $A$. japonica was an infralittoral one, showing habitat zonation. Distributions of the two species overlapped off the low-water shoreline, because a portion of the A. vulgaris population moved to the infralittoral runnel zone during ebb tide. This might be the reason why the two species were able to coexist in the surf zone (cf. Jo \& Hanamura 1993). Habitat types of A. vulgaris and A. japonica agreed with earlier results of Jo \& Hanamura (1993) and Hanamura (1997). Habitat zonation between intertidal Archaeomysis kokuboi and infralittoral $A$. japonica has also been reported at Koshirahama Beach in northeastern Japan, and A. japonica was found in the area more than $10 \mathrm{~m}$ from the high-water shoreline, which followed a seasonal movement in the position of a step structure (Takahashi \& Kawaguchi 1995). At Fukiagehama Beach in southern Japan, A. japonica was found in the area more than $60 \mathrm{~m}$ from the high-water shoreline, which corresponded to seasonal changes in the position of the low-tide terrace structure, which was in turn related to seasonal changes in the width of the intertidal zone. Iiella ohshimai was found further away from the two Archaeomysis species, and this also agreed with results by Takahashi \& Kawaguchi (1995). These results suggest that the habitat boundaries of sand-burrowing mysids depend on the morphodynamic state of each individual sandy beach.

Takahashi \& Kawaguchi $(1995,1997)$ suggested habitat zonation among different sexual maturity stages for $A$. kokuboi and A. japonica at a low-energy reflective beach, Koshirahama Beach, and emphasized differences in their responses to wave action or flow regimes near the bottom. Various developmental stages of A. vulgaris were found to overlap in their distribution at high-energy intermediate beach at Fukiagehama. At high-energy intermediate beaches, the microdistribution patterns of mysids might be disturbed and therefore show few differences among developmental stages because the wave action is stronger than at low-energy reflective beaches. 
The horizontal and vertical distribution patterns, in relation to diel and tidal rhythms, for A. vulgaris described in this study were similar to those for $A$. kokuboi (cf. Matsudaira et al. 1952, Ii 1964, Takahashi \& Kawaguchi 1997), A. vulgaris (cf. Kaneko \& Omori 2003) and Archaeomysis grebnitzkii (cf. McLachlan 1990). At nighttime low water, A. vulgaris had a wider distribution than at daytime low water, and there were differences in the vertical distribution patterns among developmental stages. A. vulgaris, like $A$. kokuboi and A. japonica, has been reported to feed in the water column at night (cf. Takahashi \& Kawaguchi 1998, Kaneko \& Omori 2003, author pers. obs.). Our laboratory observations (unpub.) at night showed that mature females became poor swimmers and are sensitive to artificial stimulation (e.g. light, percussion) because of having embryos or larvae in the marsupium, while the others are active swimmers and are insensitive to such stimulation. In fact, mature females burrowed into the sand immediately when they appeared in the water column, but the others swam about actively. Feeding activity and swimming behavior related to light conditions seems to be one of the reasons why their distribution expands offshore at night.

Fluctuations in total mean density (TMDe) at each tide suggested that non-conservative factors may influence the population of $A$. vulgaris, such as surf zone currents (bed return currents, rip currents and longshore currents), fish predation and other biological processes. In addition, the variability of measured TMDe suggests sand-burrowing mysids were probably patchily distributed in the rapidly changing surf zone, and thus it was difficult to accurately estimate their density.

In May of 2002 and 2003 at Fukiagehama, the total density of Archaeomysis vulgaris was greater at low water in the intertidal runnel than off the low-water shoreline (Fig. 6). Since salinity at low water in the intertidal runnel (mean: $18.6 \mathrm{psu}$ ) was lower than that in the infralittoral runnel or at the low-water shoreline (mean: $32.2 \mathrm{psu}$ ), it might be necessary for $A$. vulgaris to be tolerant of low salinities. Our unpublished data show that both $A$. vulgaris and $A$. japonica had a high tolerance to low salinity. All individuals of the two species survived in seawater of 8 and $16 \mathrm{psu}$ for $24 \mathrm{hr}$ at $20^{\circ} \mathrm{C}$. However, A. vulgaris and A. japonica were unable to survive in freshwater $(0 \mathrm{psu})$ for one hr at $20^{\circ} \mathrm{C}$. This suggests that A. vulgaris and A. japonica can live in the intertidal runnel during low water. Gastrosaccus spp., which are also sand-burrowing mysids that occur in the intertidal zone, have been reported to have a high tolerance to low salinities (cf. Mauchline 1980), and thus the ability to tolerate low salinities might be common to sandburrowing mysids occurring in the intertidal zone of sandy beaches. Differences in distribution patterns between sandburrowing mysids do not depend on their tolerances to low salinities but may depend on differences in their responses to surf zone currents such as the bed return current, offshore movement near the bottom, and/or be related to differences in their ability to burrow into the sandy bottom.
There are two possible ecological factors that may explain the distribution patterns of $A$. vulgaris in the intertidal runnel at low water. The first is food availability (cf. Clutter 1966, Webb et al. 1988, Webb \& Wooldridge 1990, Takahashi \& Kawaguchi 1997). Webb \& Wooldridge (1990) have interpreted the greater nocturnal presence of some mysids behind the breaker zone, compared to their daytime distribution, as a response to the increased concentration of phytoplankton caused by rip currents. At night, A. vulgaris collected at the low-water shoreline had guts containing food, whereas all of those collected in the intertidal runnel had empty guts (author's pers. obs.). Therefore, the intertidal runnel was not a major feeding area for $A$. vulgaris because they fed at night. The second hypothesis is predation avoidance (cf. Webb \& Wooldridge 1990, Takahashi \& Kawaguchi 1997). The most powerful ichthyo-predators of surf-zone mysids on southern Japan's sandy beaches, are Paralichthys olivaceus, Paraplagusia japonica, Heteromycteris japonica, Sillago japonica, Takifugu niphobles and Lateolabrax latus (Suda et al. 2002, 2004, Inoue et al. 2005, Nakane et al. 2005). According to our field observations (unpub.), such ichthyo-predators were not found in the intertidal runnel at low water. Certain species of fishes utilize the infralittoral runnel as a habitat for feeding or as a nursery, but rarely the intertidal runnel (cf. Harvey 1998, Layman 2000). Therefore, the predation avoidance hypothesis could be applicable for A. vulgaris, since it could survive buried in the sand in the intertidal runnel with very little seawater during low water.

Takahashi \& Kawaguchi (2004) stated that A. kokuboi and $A$. japonica had adapted differently to their respective intertidal and infralittoral beach habitats. The high reproductive potential of intertidal A. kokuboi was an adaptation to its high mortality rate caused by unpredictable events such as storms, or extreme changes in temperature or salinity. In contrast, the efficient reproduction of $A$. japonica during the high water temperature season was an adaptation to the infralittoral habitat where more predictable events such as seasonal variation of temperature prevailed. To understand the distribution patterns characteristic of $A$. vulgaris, the reproductive biology of $A$. vulgaris must be studied. Beach morphodynamic states also should be taken into consideration to better understand the distribution patterns of mysids on sandy beaches.

\section{Acknowledgments}

The authors would like to thank Mr. M. Haraguchi and the people in Kyouden district, Kagoshima Prefecture, for offering accommodation facilities during the field sampling. We thank students of the Lab. of Fisheries Biology and Environment, National Fisheries University, for their help in mysid sampling. Thanks are also due to Drs. S. Nishida and Iain McTaggart for helpful comments on the manuscript. We appreciate the valuable comments of anonymous reviewers. 


\section{References}

Brown AC, McLachlan A (1990) Ecology of Sandy Shores. Elsevier, Amsterdam, 328 pp.

Clutter RI (1966) Zonation of nearshore mysids. Ecology 48: 200-208.

Hanamura Y (1997) Review of the taxonomy and biogeography of shallow-water mysids of the genus Archaeomysis (Crustacea: Mysidacea) in the North Pacific Ocean. J Nat Hist 31: 669-711.

Hanamura Y (1999) Seasonal abundance and life cycle of $\mathrm{Ar}$ chaeomysis articulata (Crustacea: Mysidacea) on a sandy beach of western Hokkaido, Japan. J Nat Hist 33: 1811-1830.

Harvey C (1998) Use of sandy beach habitat by Fundulus majalis, a surf-zone fish. Mar Ecol Prog Ser 164: 307-310.

Ii N (1964) Mysidae, Fauna Japonica. Biogeographical Society of Japan, Tokyo, 610 pp.

Inoue T, Suda Y, Sano M (2005) Food habits of fishes in the surf zone of a sandy beach at Sanrimatsubara, Fukuoka Prefecture, Japan. Ichthyol Res 52: 9-14.

JCG (Japan Coast Guard) (2001). Kagoshima. In: Tide tables, Vol. 1, Japan and its vicinities (ed The hydrographic and oceanographic department). JCG, Tokyo, pp. 243-245. (in Japanese)

JCG (Japan Coast Guard) (2002). Kagoshima. In: Tide tables, Vol. 1, Japan and its vicinities (ed The hydrographic and oceanographic department). JCG, Tokyo, pp. 243-245. (in Japanese)

Jo SG, Hanamura Y (1993) Redescription of mysid Archaeomysis vulgaris (Nakazawa, 1910) comb. nov. (Crustacea: Mysidacea: Gastrosaccinae). Korean J Syst Zool 9: 103-113.

Kaneko K, Omori M (2003) Diel and tidal migrations and predator-prey relationships of macrobenthic animals in intertidal sandy beaches of Sendai Bay, northern Japan. Benthos Res 58: $43-49$.

Layman CA (2000) Fish assemblage structure of the shallow ocean surf-zone on the eastern shore of Virginia Barrier Islands. Est Coast Shelf Sci 51: 201-213.

Marcomini CS, Penchaszadeh P, Lopez RA, Luzzatto D (2002) Beach morphodynamics and clam (Donax hanleyanus) densities in Buenos Aires, Argentina. J Coast Res 18: 601-611.

Matsudaira C, Kariya T, Tsuda T (1952) The study on the biology of a mysid, Gastrosaccus vulgaris Nakazawa. Tohoku J Agricult Res 3: 155-174.

Mauchline J (1980) The biology of mysids. In: Advances in Marine Biology Vol. 18 (ed Blaxter JHS, Russell FS, Yonge M). Academic Press, London, pp. 3-369.

McLachlan A (1990) Dissipative beaches and macrofauna communities on exposed intertidal sands. J Coast Res 6: 57-71.

McLachlan A, Hesp P (1984) Faunal response to morphology and water circulation of a sandy beach with cusps. Mar Ecol Prog Ser 19: 133-144.

Nakane Y, Suda Y, Ohtomi J, Hayakawa Y, Murai T (2005) Nearshore ichthyofauna in the intermediate sandy beach, Fuki- agehama Beach, Kagoshima Prefecture, Japan. J National Fish Univ 53: 57-70. (in Japanese with English Abstract)

Nonomura T, Hayakawa Y, Suda Y, Ohtomi J (2005) Practical identification of the sand-burrowing mysid, Archaeomysis vulgaris (Crustacea: Mysidacea) and its biological characteristics. Plankton Biol Ecol 52: 48-57.

Shimode S, Shirayama Y (2006) Diel vertical migration and life strategies of two phytal-dwelling harpacticoids, Ambunguipes rufocincta and Eudactylops spectabilis. Plankton Benthos Res 1: 42-53.

Short AD (1999) Handbook of beach and shoreface morphodynamics. John Wiley \& Sons, England, 379 pp.

Suda Y, Inoue T, Nakamura M, Masuda N, Doi H, Murai T (2004) Nearshore ichthyofauna in the intermediate sandy beach, Doigahama Beach, Yamaguchi Prefecture, Japan. J National Fish Univ 52: 11-29.

Suda Y, Inoue T, Uchida H (2002) Fish communities in the surf zone of a protected sandy beach at Doigahama, Yamaguchi Prefecture, Japan. Est Coast Shelf Sci 55: 81-96.

Takahashi K, Kawaguchi K (1995) Inter- and intraspecific zonation in three species of sand-burrowing mysids, Archaeomysis kokuboi, A. grebnitzkii and Iiella ohshimai, in Otsuchi Bay, northeastern Japan. Mar Ecol Prog Ser 116: 75-84.

Takahashi K, Kawaguchi K (1996) Practical key characters to identify the closely related sand-burrowing mysids, Archaeomysis kokuboi and A. japonica (Mysidacea: Gastrosaccinae) throughout all developmental stages. Bull Plankton Soc Japan 43: 133-137.

Takahashi K, Kawaguchi K (1997) Diel and tidal migrations of the sand-burrowing mysids, Archaeomysis kokuboi, A. japonica and Iiella ohshimai, in Otsuchi Bay, northeastern Japan. Mar Ecol Prog Ser 148: 95-107.

Takahashi K, Kawaguchi K (1998) Diet and feeding rhythm of the sand-burrowing mysids Archaeomysis kokuboi and A. japonica in Otsuchi Bay, northeastern Japan. Mar Ecol Prog Ser 162: 191-199.

Takahashi K, Kawaguchi K (2004) Reproductive biology of the intertidal and infralittoral mysids Archaeomysis kokuboi and A. japonica on a sandy beach in NE Japan. Mar Ecol Prog Ser 283: 219-231.

Webb P, Perissinotto R, Wooldridge TH (1988) Diet and feeding of Gastrosaccus psammodytes (Crustacea, Mysidacea) with special reference to the surf diatom Anaulus birostratus. Mar Ecol Prog Ser 45: 255-261.

Webb P, Wooldridge TH (1990) Diel horizontal migration of Mesopodopsis slabberi (Crustacea: Mysidacea) in Algoa Bay, southern Africa. Mar Ecol Prog Ser 62: 73-77.

Wright LD, Thom BG (1977) Coastal depositional landforms: a morphodynamic approach. Prog Phys Geog 1: 412-459.

Zar JH (1999) Biostatistical Analysis, 4th ed. Prentice-Hall, New Jersey, 929 pp. 